\title{
Émile Durkheim e o socialismo
}

\section{Émile Durkheim and socialism}

Sidnei Ferreira de Vares ${ }^{1}$

\section{Introdução}

No interior da teoria sociológica, Émile Durkheim (1858-1917) é comumente visto como um autor avesso ao socialismo. Seus trabalhos representariam uma oposição à energia revolucionária contida nas doutrinas socialistas. O que poucos sabem, porém, é que o sociólogo francês dedicou parte de seus escritos ao assunto. $\mathrm{O}$ fato, aparentemente inusitado, tem uma razão de ser. Durante a segunda metade do século XIX, Durkheim testemunhou a difusão das ideias socialistas por toda a Europa, inclusive na França, seu país de origem. Também acompanhou, ainda no tempo em que lecionava em Bordeaux, a conversão de muitos de seus alunos ao socialismo. Desde a publicação de seu primeiro grande trabalho, $D a$ Divisão do Trabalho Social, é possível avistar seu interesse pelo conjunto de doutrinas em questão. Embora a referida obra tenha culminado em uma teoria sobre os tipos de solidariedade concernentes aos modelos sociais tradicionais e modernos, segundo seu sobrinho Marcel Mauss a intenção inicial de Durkheim era analisar "a relação entre individualismo e socialismo", tema que o atraía desde a época de estudante na École Normale Supérieure.

Todavia, se na altura em que redigiu sua tese doutoral o sociólogo tinha conhecimento das teorias de Saint-Simon e de Proudhon, bem como havia tomado contato com alguns escritos de Marx, seus conhecimentos acerca das doutrinas socialistas ainda estavam longe de ser consistentes. O único tipo de socialismo que conhecia melhor nesta primeira fase de sua carreira era a teoria social reformista dos economistas e juristas alemães, graças à viagem que

\footnotetext{
${ }^{1}$ Doutor e mestre em Educação pela USP. Graduado em História. Professor dos cursos de História e Filosofia do UNIFAI e do curso de Pedagogia do UNISANTANNA. E-mail: vares76@terra.com.br
} 
realizou àquele país poucos anos antes ${ }^{2}$. Uma incursão mais profunda só ocorreria entre os anos de 1895 e 1896, período em que Durkheim ministrou uma série de conferências sobre o assunto na Faculdade de Letras de Bordeaux, publicadas anos depois de sua morte com o título "Le Socialisme"3. Inicialmente, este estudo estava projetado para ser mais amplo. O objetivo de Durkheim era investigar a origem e o desenvolvimento das ideias socialistas modernas, destacando alguns de seus mais significativos representantes, tais como SaintSimon, Sismondi, Lassalle, Marx e Engels. O empreendimento, entretanto, não chegou a ser totalmente concluído. Seu envolvimento na organização da Revue Année Sociologique impactou negativamente na consecução desses propósitos, e apenas as partes relativas à definição, à origem e à teoria de Saint-Simon lograram êxito. Não obstante, este trabalho constitui um importante manancial de informações a respeito da visão durkheimiana acerca do socialismo. Nessas preleções encontramos, por exemplo, uma definição das ideias socialistas, um estudo detalhado sobre o seu surgimento, além de uma importante distinção entre comunismo e socialismo. Ademais, as análises empreendidas deixam transparecer certa preocupação em relação à agudização das tensões sociais, decorrentes, na visão do autor, do distanciamento das esferas econômica e moral no contexto do mundo moderno.

Mas, afinal, qual a impressão de Durkheim sobre o conjunto de doutrinas socialistas? Em que medida o sociólogo francês mostra-se um crítico desta tradição? Qual o propósito do autor ao projetar todo um curso sobre o tema?

Objetivando responder adequadamente a essas questões, o presente artigo divide-se em três partes. Na primeira, analisaremos a definição e a origem do socialismo a partir da ótica durkheimiana. Com isso, intentamos verificar, dentro do quadro geral de sua teoria, o entendimento do autor acerca do surgimento das teorias socialistas na modernidade, bem como a diferenciação por ele estabelecida entre estas e as teorias comunistas. Na segunda parte, apresentaremos as principais críticas de Durkheim ao socialismo, em especial à integração entre as atividades políticas e as atividades produtivas e ao papel do Estado nas sociedades caracterizadas por uma acentuada divisão do trabalho. Na terceira parte,

\footnotetext{
${ }^{2}$ Durante o biênio de 1885-1886, após ter sido contemplado com uma bolsa de estudos pelo governo francês, Durkheim se transferiu para a Alemanha, onde realizou alguns cursos de aprimoramento profissional. Em seu retorno, no meio do ano de 1886, começou a levantar o material para a produção de sua tese de doutorado.

${ }^{3}$ No Brasil, uma edição organizada por Luiz Carlos Fridman, intitulada Émile Durkheim e Max Weber: socialismo, trás em seu corpo os dois primeiros capítulos da obra Le Socialisme do sociólogo francês, atinentes à definição e o surgimento do socialismo, além de uma conferência do sociólogo alemão sobre o mesmo tema. É esta a edição que servirá de base para o presente artigo. Consultar as referências bibliográficas.
} 
examinaremos as estratégias empregadas pelo sociólogo francês no sentido de superar os dilemas com os quais os socialistas se defrontaram e, por fim, pontuaremos as divergências e possíveis convergências entre os dois sistemas sociológicos.

\section{Socialismo: definição e origem}

Tal como informamos na introdução, o curso que Durkheim dedicou ao socialismo estava inicialmente programado para ser um estudo histórico de grande fôlego sobre o conjunto das doutrinas socialistas. Entretanto, somente as partes referentes à origem e à definição foram inteiramente concluídas. Apesar dos percalços enfrentados pelo autor, que o impossibilitaram de atingir suas metas originais, é possível, a partir desse material, identificar os elementos essenciais de sua interpretação. Trata-se, pois, de um estudo fundamental para todos aqueles que se interessam pelo assunto, podendo contribuir para despertar o pensamento para uma avaliação das vias de construção de uma sociedade isonômica, onde os indivíduos possam realizar as suas potencialidades criativas. Nele, percebemos claramente o esforço do mestre francês em compreender as ideias centrais do socialismo, a adesão dos homens às suas promessas, e, sobretudo, a engenharia social que seus representantes intentavam realizar.

Fiel à postura adotada em seus primeiros trabalhos, nos quais se empenha em determinar do exterior os fenômenos sociais, Durkheim encara o socialismo como uma realidade objetiva, confrontando-o com aqueles sistemas de ideias que, num contexto social mais amplo, antecederam seu surgimento. Circunscrito a um tempo e espaço específicos, o socialismo, devido às suas especulações sobre o futuro e aos seus planos de reconstrução das ordens sociais atuais, não pode ser considerado uma ciência, se por isso entendermos todo esforço de pesquisa para descrever e explicar um objeto atual, traduzindo-o em linguagem inteligível. Ele desponta, portanto, como um ideal contrário à exploração que recaiu sobre os trabalhadores europeus a partir das transformações sociais e econômicas processadas no decorrer da segunda metade do século XVIII, na medida em que se preocupa mais com o que deve ser do que com o que é. Se, por um lado, os socialistas jamais desdenharam do apoio dos fatos, por outro, os diversos tipos de correntes por eles criadas basearam-se muito mais em um sentimento de indignação frente à realidade social do que em uma postura autenticamente científica. 
Foi a paixão que inspirou esses sistemas; o que lhes deu nascimento e o que constitui sua força é a sede de justiça mais perfeita, é a piedade pela miséria das classes trabalhadoras, é um vago sentimento de perturbação que impera nas sociedades contemporâneas etc. O socialismo não é uma ciência, uma sociologia em miniatura, é um grito de dor e, por vezes, de cólera, lançado pelos homens que mais vivamente sentem nosso mal-estar coletivo (Durkheim In: Fridman, 1993, p.37).

Nesse sentido, o impulso precípuo das teorias socialistas é a percepção do estado caótico da vida econômica moderna, que, apartada dos modos tradicionais de produção, engendrou um conjunto de condições desfavoráveis à maior parte da população dos países industrializados.

Logo na primeira lição de seu curso, objetivando saber o que é o socialismo, Durkheim apresenta aos leitores seu método de análise: interrogar as diferentes doutrinas denominadas socialistas, observando-as e comparando-as, para extrair seus traços mais essenciais. O sociólogo quer, assim, evitar estender o qualificativo "socialismo" a fenômenos que nada têm a ver com ele, por isso se cerca de todos os cuidados possíveis frente a esta ordem de fatos. Desse modo, afirma Durkheim, devem ser consideradas "socialistas" todas as doutrinas que reivindicam a ligação mais ou menos completa entre as funções comerciais e industriais, ou de algumas delas, mesmo difusas, aos órgãos diretores e conscientes da sociedade. Como faz questão de salientar, não se trata de subordinar os interesses econômicos aos interesses políticos, mas apenas estabelecer uma comunicação constante entre eles. Garantidas essas condições, é bem mais provável que o inverso se dê: os interesses comerciais e industriais afetarão muito mais o funcionamento do órgão governamental. Em outros termos, as funções propriamente políticas, que especificam o Estado, perderão sua razão de ser, e, por conseguinte, este passará a desempenhar funções meramente econômicas. Como explicita a famosa tese de Saint-Simon, citada por Durkheim, na sociedade industrial a administração das coisas tende a substituir a administração das pessoas.

Aprofundemos melhor este ponto. Na perspectiva socialista, o Estado tem a função de administrar a produção, gerando riqueza suficiente para o bem de todos os membros da sociedade. Nenhuma doutrina socialista, entretanto, preconiza que o consumo deva tornar-se objeto de controle. Sendo assim, cada indivíduo tem liberdade de usufruir dos frutos da produção para a sua própria realização pessoal.

Segundo Durkheim, existe uma linha de descendência direta entre os iluministas, a tradição liberal - tanto na teoria política quanto na teoria econômica - e os socialistas. Dos 
primeiros, o socialismo herda a autonomia da razão em relação às tradições e a noção de igualdade social. Já dos segundos, o socialismo herda a centralidade conferida à atividade econômica no mundo moderno. No entanto, diferentemente dos teóricos liberais, os socialistas defendem que as atividades industriais não podem funcionar sem nenhum tipo de coordenação. Seu principal objetivo, mais do que a defesa da classe operária face aos interesses da burguesia, é a regulamentação centralizada da produção. Ainda assim, para que a atividade produtiva deixe de contemplar os interesses de uma classe social particular e passe a atender às necessidades da sociedade em seu conjunto, os socialistas - particularmente os de vertente marxista - reivindicam a abolição das classes em geral, o que, por suposto, levaria à extinção da ordem social capitalista.

Na segunda lição, Durkheim enceta uma importante distinção entre "socialismo" e “comunismo". Embora empregado amiúde como sinônimo de comunismo, o socialismo difere daquele por ser um termo relativamente novo no plano histórico, coincidindo com o surgimento de sociedades nas quais a divisão do trabalho se encontra em estágio avançado.

As ideias comunistas, por outro lado, não são criações de uma época e de um lugar específicos, aparecendo regularmente no curso da história. Elas expressam as personalidades de alguns pensadores que, isoladamente, preocuparam-se em atingir modelos sociais justos. São estes os casos de Platão, Morus, Campanella, entre outros. ${ }^{4}$ Trata-se, pois, de espíritos generosos, tomados de nobreza e dignidade, que elaboraram doutrinas essencialmente morais, identificando na propriedade privada a origem do acúmulo desigual da riqueza. Por isso, argumenta o mestre francês, o fulcro do pensamento comunista é a separação entre a esfera econômica e a esfera política, e não a assimilação de ambas como defendem os socialistas. Esse distanciamento, na perspectiva dos comunistas, evitaria à riqueza tornar-se fonte de degenerescência do Estado. Os comunistas são, portanto, ascéticos em relação aos efeitos da riqueza. A riqueza material é entendida como um mal que só pode ser combatido por meio de restrições severas à acumulação, pois, à medida que esta estimula os egoísmos individuais, contribui para a corrupção pública. Em suma, quanto mais afastado o Estado estiver da vida pública, menor os riscos de perverter-se. Na República ideal de Platão, por exemplo, os governantes têm o direito de intervir na vida econômica, porém, a classe produtora não dispõe do direito de influenciar a conduta do governo. Já em sua Utopia, Morus afirma que cada

\footnotetext{
${ }^{4} \mathrm{Na}$ ótica de Durkheim, os autores mencionados estariam alinhados ao ideal comunista, na medida em que eles defendem o controle sobre a riqueza socialmente produzida, além de apregoarem a submissão da atividade produtiva aos ditames do Estado, o que na prática equivaleria separar essas duas esferas.
} 
indivíduo trabalha como bem entender, devendo apenas ser controlado para não ficar desocupado. Contudo, segundo Durkheim, o que cada um produz não lhe pertence, pois não pode dispor do produto de seu trabalho de acordo com sua vontade. Cabe-lhe entregar o que foi produzido à comunidade, para que, posteriormente, possa ser usado coletivamente. Como podemos entrever a partir da análise durkheimiana, para os comunistas a propriedade privada é a fonte de todo o egoísmo, e este, por sua vez, nasce da imoralidade. Disso decorre o esforço de seus representantes em resguardar a autonomia do Estado.

A premissa básica do socialismo, por seu turno, é de que a produção tem que ser centralizada nas mãos do Estado, restringindo a influência governamental à administração da economia. A visão que sustentam sobre a riqueza está longe de ser pessimista como a dos comunistas. Conquanto defendam o controle e a regulação da produção, os socialistas acreditam que esta deve ser estimulada, gerando riqueza em abundância para o bem estar de todos. Nas palavras de Durkheim:

O socialismo não se reduz a uma questão de salários, ou, como se diz, de estômago. É, antes de mais nada, uma aspiração de rearranjo do corpo social que tem por efeito situar de um outro modo o aparelho industrial no conjunto do organismo, tirá-lo da sombra em que funcionava automaticamente, chamá-lo à luz e ao controle da consciência (Durkheim In: Fridman, 1993, p. 61).

Excetuando a tentativa de combater situações nas quais os interesses individuais se sobrepõem aos interesses coletivos, ambos os modelos em nada se assemelham. O único ponto de convergência entre eles, indubitavelmente, reside na crítica ao livre exercício do egoísmo. Mas, até nisso diferem radicalmente, pois enquanto os comunistas vislumbram eliminar completamente o egoísmo, os socialistas só consideram perigosa a apropriação individual de grandes empreendimentos econômicos, o que, na interpretação durkheimiana, leva estes últimos a confundir o secundário com o essencial. Em uma clara alusão às ideias defendidas em Da Divisão do Trabalho Social, Durkheim conclui a segunda lição do seguinte modo:

Entre essas duas espécies de arranjos sociais há, pois, uma distância como a que separa a organização de certas colônias de pólipose e a dos animais superiores. Na primeira, cada uma dos indivíduos associados caça por sua própria conta, a título privado; mas o que ele captura é atirado em um estômago comum, e o indivíduo não pode ter sua parcela na riqueza comum, ou seja, ele não pode comer sem que toda a sociedade coma ao mesmo tempo. Entre os vertebrados, ao contrário, cada órgão é obrigado, em seu funcionamento, a se conformar com as regras que são destinadas a harmonizá-lo com os outros; é o sistema nervoso que assegura essa consonância. 
Mas cada órgão, e, em cada órgão, cada tecido, e, em cada tecido, cada célula nutrem-se à parte, livremente, sem que, por isso, sejam dependentes dos outros. Cada uma das grandes partes do organismo tem mesmo seu alimento especial. O abismo não é menos considerável entre as duas concepções sociais que tão frequentemente foram aproximadas (Durkheim In: Fridman, 1993, p. 73-74).

Analisemos, pois, o teor das críticas empreendidas por Durkheim ao socialismo, pretensamente o modelo social mais adequado à superação do malaise moderno, contidas na terceira lição de seu curso.

\section{Durkheim e as críticas ao socialismo}

Conforme pontuamos acima, Durkheim entende que as doutrinas socialistas constituem um fato historicamente recente. Estas proliferam no interior das transformações políticas, econômicas e sociais processadas, sobremaneira, nos últimos decênios do século XVIII. Desse ponto de vista, diferentemente do comunismo, cuja presença na história é mais ou menos esporádica, o socialismo está circunscrito a um tempo e espaço dados, surgindo como uma tentativa de equalizar as desigualdades geradas pelo avanço acelerado da industrialização. Porém, ainda que avalie positivamente as intenções socialistas, na medida em que entre elas está a de superar a opressão que recai sobre os trabalhadores, o sociólogo reluta em aceitar as soluções apresentadas por seus representantes. Mas, qual o motivo ou motivos desta discordância?

Antes de tentarmos responder a essa questão, é mister resgatar alguns pontos importantes. Tanto a Revolução Francesa quanto a Revolução Industrial subverteram definitivamente a antiga ordem social, destronando monarcas e/ou modificando relações políticas e sociais seculares. Os efeitos desse processo não tardaram a se fazer sentir, e as desigualdades políticas converteram-se em desigualdades econômicas. Em outras palavras, a sociedade moderna descobriu a força inerente às relações de mercado. Houve, todavia, um encontro fundamental entre as aspirações igualitárias, estimuladas pelo contexto revolucionário, e a consciência da anarquia econômica provocada pela expansão da indústria nascente. Foi esta conjunção do protesto contra as desigualdades, assinala o autor, que favoreceu o surgimento do socialismo.

De forma confusa, o conjunto de doutrinas socialistas compreendia três grupos de ideias: a noção de um novo despertar religioso, um corpo doutrinário socialista e, por fim, a 
concepção de uma sociologia científica. Esses três grupos, à primeira vista diferentes e até mesmo opostos uns aos outros, na verdade derivavam de uma circunstância histórica comum, sintetizada pelas sucessivas crises políticas e sociais. Cada um deles expressava, parcialmente, aspectos dessa mesma desordem. O movimento religioso, por exemplo, surgiu da tentativa de controlar o egoísmo e de recriar a autoridade moral. Tal movimento, entretanto, mostrou-se inadequado à medida que intentava restabelecer antigas formas de dominação eclesiásticas apropriadas, apenas, aos modelos sociais tradicionais. Em relação ao socialismo, embora seus representantes reconhecessem o esgotamento da antiga ordem e que, consequentemente, as instituições tradicionais tinham que dar lugar a novas formas de organização social, pretendia remediar a situação de crise que havia se instalado através de um programa de controle das atividades econômicas. O ímpeto em direção à sociologia, por sua vez, ancorava-se no desejo de explicar as transformações enfrentadas pela sociedade europeia.

Para Durkheim, os socialistas tiveram o mérito de perceber o dilema moderno: a contradição entre a maior capacidade produtiva e a miséria de grande parte da população. No entanto, a solução por eles apresentada reduzia-se à reorganização consciente da vida econômica, ignorando completamente outros aspectos da vida social. É esse último ponto, em particular, que o sociólogo rechaça. Isto porque, em sua leitura, a questão social não poderia ser superada através de reformas inspiradas exclusivamente no espírito de caridade. Era necessário muito mais do que o controle da atividade produtiva para equalizar as tensões decorrentes das desigualdades provocadas pelo advento da industrialização.

Como bem observa Anthony Giddens (1978), Durkheim fazia três críticas principais às ideias socialistas, tais como ele as definia. São elas: (a) o tipo de regulamentação proposta pelos socialistas no que se refere à sociedade moderna; (b) os efeitos desta regulamentação para o Estado; (c) e o papel da luta de classes na consecução de uma sociedade mais igualitária.

Em relação à primeira delas, Durkheim opõe-se às soluções puramente econômicas levadas a cabo pelos socialistas, pois, embora almejassem superar a visão dos utilitaristas e dos economistas clássicos - responsáveis por reduzir a sociedade a relações contratuais - , ao submeterem a produção à direção consciente do Estado os socialistas repetem o mesmo 
equívoco daqueles, isto é, não conseguem perceber que qualquer mudança econômica deve ser acompanhada do desenvolvimento da regulamentação moral ${ }^{5}$.

Não por acaso, a segunda crítica dirige-se à concepção de Estado defendida pelos socialistas. Durkheim não aceita a tese segundo a qual o Estado deve transcender seu caráter político, convertendo-se em centro de coordenação econômica. Isto porque ele não só perderia sua identidade, como também tornar-se-ia uma instituição entre outras na sociedade civil. Mas a crítica durkheimiana contém outro aspecto importante, a saber, a ineficiência das doutrinas socialistas em superar a tensão entre a noção de igualdade e o controle estatal da economia. Como parece sugerir Durkheim, os teóricos do socialismo não foram capazes de demonstrar de que modo o controle da produção poderia produzir uma sociedade mais justa, visto assentarem sua argumentação na geração de fartura material e não na redistribuição igualitária da renda, além, é claro, de ignorarem completamente a importância do tema da moralidade para a organização racional da sociedade. Com efeito, na visão do autor, o tema da igualdade encontra-se "solto" no desenvolvimento das ideias socialistas. Durkheim deixa escapar, assim, o seu posicionamento a respeito do Estado: este não pode nem deve sucumbir à dinâmica da vida econômica sob o risco de descaracterizar-se, isto é, de perder sua função política e moral ${ }^{6}$.

Por último, Durkheim faz uma crítica pontual à tese marxista da imprescindibilidade da luta de classes para a realização do socialismo. Na leitura do mestre francês, a preocupação central do socialismo gravita em torno da necessidade de uma regulação econômica. Destarte, todas as outras preocupações são secundárias, produtos da inspiração de um comunismo deslocado do tempo e espaço. A luta pela melhoria da situação dos trabalhadores, por exemplo, deve ser vista muito mais como consequência da amálgama entre Estado e economia, do que como elemento deflagrador do socialismo.

\footnotetext{
${ }^{5}$ É até certo ponto fácil notar que, ao acusar os socialistas de apontarem soluções puramente econômicas para os males do mundo moderno, Durkheim está invocando as críticas outrora feitas tanto aos economistas clássicos quanto aos utilitaristas em Da Divisão do Trabalho Social. Como fez questão de enfatizar nesta obra, há um elemento não-contratual no contrato, que se apresenta na forma de regras, normas e valores socialmente constituídos. Por isso, insiste o autor, uma solução efetiva aos dilemas modernos não pode se restringir a um conjunto de reformulações econômicas, devendo, necessariamente, estender-se ao campo da moralidade.

${ }^{6}$ A questão do Estado nas sociedades modernas será retomada por Durkheim não só em suas Lições de Sociologia, obra publicada tardiamente, mas, também, no Prefácio à Segunda Edição de Da Divisão do Trabalho Social e na parte final de $O$ Suicídio. Nesses textos, portanto, é possível verificar mais profundamente o modo como o sociólogo encara as funções estatais, inclusive no que se refere à atividade produtiva e à sociedade civil. Desenvolveremos melhor este ponto na próxima seção.
} 
Em suma, Durkheim vê o movimento socialista como o resultado de uma conjuntura histórica tardia, marcada por uma ordem de manifestações sociais cuja complexidade e mobilidade sociais são refratárias a uma regulamentação invariável e simplista. Trata-se, pois, de uma reação à anomia econômica moderna, na medida em que seus representantes insistem em transferir para o campo da consciência diretiva as funções que se encontram dispersas no meio social. Porém, ao fazê-lo, os socialistas ingenuamente atribuem uma ênfase demasiada aos aspectos organizacionais, ignorando por completo os aspectos políticos e morais. O erro socialista, com efeito, consiste em reduzir o Estado a um traço de união entre as diferentes relações industriais e comerciais, das quais não é senão uma espécie de sensorium commune.

\section{O sentido do "socialismo" durkheimiano}

Posto que Durkheim refute abertamente a possibilidade de uma reformulação radical da sociedade contemporânea, ele prevê uma tendência bem definida para a superação das distinções de classe. Tanto em suas Lições de Sociologia quanto em O Suicídio, mas também no prefácio escrito por ocasião da segunda edição de Da Divisão do Trabalho Social, o autor indica os caminhos que considera mais viáveis à consecução de uma sociedade igualitária. Ainda que reconheça a necessidade de programas assistenciais e outras medidas com vistas a melhorar as condições de vida dos trabalhadores mais pobres, Durkheim insiste na regulamentação das atividades econômicas, salientando, entretanto, que esta não deve ser inteiramente confiada ao Estado.

No primeiro trabalho acima mencionado, o sociólogo francês oferece uma teoria do Estado que se harmoniza com o caráter geral de sua sociologia. Todavia, o enfoque durkheimiano contém algumas peculiaridades. Em primeiro lugar, o autor rompe com a famosa definição de Max Weber segundo a qual o Estado se define tanto pelo monopólio legítimo da violência quanto pela delimitação de uma área territorial fixa. De acordo com Durkheim, a territorialidade constitui um fenômeno relativamente recente, que tem conexão com outros fatores além do próprio Estado. Para fazer valer sua tese, ele recorda que algumas sociedades nômades possuíram aparelhos políticos tão ou mais complexos do que algumas sociedades convencionais. Durkheim também critica parcialmente a tese de que toda sociedade política comporta uma divisão de autoridade, isto é, uma separação entre os que mandam e os que obedecem. Isto porque, em termos históricos, nem todas as sociedades 
podem ser assim definidas, e nem todos os grupos que exibem essa divisão são sociedades inteiras. O autor observa, por exemplo, que as sociedades simples carecem de um sistema diferenciado de autoridade administrativa. Em contrapartida, salienta que algumas instituições no interior de sociedades consolidadas apresentam estruturas similares a um sistema governamental, como no caso da família patriarcal romana. Não obstante, por sociedade política Durkheim entende "uma sociedade formada pela reunião de um número mais ou menos considerável de grupos sociais secundários, submetidos a uma mesma autoridade, que por sua vez não depende de nenhuma autoridade superior regularmente constituída" (Durkheim, 2002, p. 63).

No que se refere ao Estado, Durkheim afirma se tratar de um "órgão-pensante", formado por um grupo especial de funcionários encarregados de representar essa autoridade à qual está submetida toda a sociedade política, ou seja, todo o conjunto de grupos secundários. Ele encara a relação entre Estado, sociedade e indivíduo de um modo bastante peculiar, que em nada se assemelha às visões que, naquela época, ainda tinham ampla repercussão, tais como as de Hegel, dos utilitaristas e socialistas. Na concepção hegeliana, por exemplo, o Estado é elevado acima da sociedade, e o indivíduo, reduzido a um instrumento da realização das ambições daquele. Já os utilitaristas consideram que a esfera da autoridade estatal deve restringir-se à proteção dos contratos, interferindo o menos possível no livre jogo do mercado. Os socialistas, por sua vez, desejam estender o Estado na direção do controle da vida econômica, fundindo-o com a sociedade. Ora, o mestre francês rejeita todas essas visões, pois em sua concepção as funções do Estado vão muito além das funções políticas ou econômicas. Sobretudo a ideia propugnada pelos socialistas de que a divisão entre o Estado e a sociedade pode ser eliminada é entendida pelo autor como um movimento de retorno a um tipo de organização social hoje obsoleta, que nega a complexidade inerente ao aumento da divisão do trabalho nas sociedades modernas. Isto, porém, não significa uma defesa nem do Estado total nem do Estado mínimo. Conforme expôs na parte final de O Suicídio, os perigos de um Estado autoritário - que sufoque as liberdades individuais - ou de um Estado fraco atravessado por interesses particulares - estão sempre presentes e podem, eventualmente, engendrar uma verdadeira "monstruosidade sociológica".

Por conta disso, em grande parte de seu prefácio à segunda edição de Da Divisão do Trabalho Social, Durkheim tenta justificar a importância das antigas corporações profissionais, as quais, na efervescência da Revolução Francesa, foram precipitadamente 
abolidas. Para ele, as corporações cumprem o importante papel de aproximar o Estado máquina política demasiadamente pesada - do indivíduo - que no mundo moderno vê-se atomizado devido ao avanço da economia de mercado, a ausência de órgãos reguladores e ao declínio de outras instituições sociais, sobretudo grupos domésticos tais como a família. $\mathrm{Na}$ medida em que a diferenciação ocupacional no mundo moderno ocorre desacompanhada de uma regulação adequada, o que só faz aumentar as tensões sociais, o resgate desses órgãossecundários se faz necessário. Assim, caberia às corporações profissionais organizar as demandas da sociedade civil, geralmente dispersas, estabelecendo um diálogo com o Estado, no sentido de comunicar-lhe as reivindicações e necessidades dos indivíduos. Como assevera o autor, só um grupo muito próximo às atividades laborais poderia dar conta de moralizá-las. Durkheim chega mesmo a prenunciar o protagonismo desses organismos face ao desenvolvimento da divisão do trabalho:

As corporações do futuro terão uma complexidade de atribuições ainda maior, devido à sua maior amplitude. Em torno de suas funções propriamente profissionais virão agrupar-se outras, que cabem atualmente aos municípios ou as sociedades privadas (Durkheim, 2008, p. XXXV).

Para Durkheim, as corporações profissionais têm o dever de cuidar da educação de seus membros, organizando cursos, concertos, representações dramáticas etc., além de também ser sua responsabilidade regulamentar a quantidade de trabalho, a remuneração adequada a cada atividade profissional e até mesmo a transmissão das heranças. A ênfase que Durkheim atribui aos agrupamentos profissionais tem uma razão de ser, a saber, intermediar as relações entre o Estado e o indivíduo, de tal modo que ambos mantenham sua autonomia. Ele procura apresentar uma alternativa tanto à servidão quanto à anarquia. Segundo o autor, conquanto o Estado, longe de obliterar o individualismo, tenha contribuído para o seu desenvolvimento, os riscos de distorções estão sempre presentes, e, por isso, esses órgãos secundários se fazem necessários, impedindo que um ou outro pólo torne-se hegemônico.

Posto isto, cumpre perguntar: seria Durkheim de todo refratário ao socialismo ou, em alguma medida, haveria algum tipo de aproximação entre eles?

Tal indagação pode soar infundada, sobretudo se considerarmos as críticas que Durkheim dirigiu ao socialismo. Contudo, cumpre observar que Durkheim jamais deixou de interagir com o pensamento socialista. Conforme Irvin Zeitlin (1973), a sociologia durkheimiana tem um débito enorme com a filosofia de Saint-Simon, por exemplo. Ademais, 
Durkheim teve como um de seus melhores amigos o socialista Jean Jaurès ${ }^{7}$, que, segundo Marcel Mauss, glorificava publicamente a sua obra. Aliás, o mesmo Mauss, em sua introdução ao curso sobre o socialismo preparado por seu tio, afirma que Durkheim "simpatizava com os socialistas, com Jaurès, com o socialismo", porém, "nunca se entregou a eles". Em que consistiria, então, essa "simpatia"?

Há, aqui, parece-nos, um ponto de aproximação entre eles: o da crítica às teorias liberais da economia clássica. Em outros termos, tanto Durkheim quanto os socialistas colocam em xeque a tese de que a sociedade é um conglomerado de indivíduos que, movidos pelo autointeresse, se relacionam através de contratos livremente fixados; ou de que a dinâmica econômica, por si só, é capaz de superar os conflitos que assolam a sociedade moderna. Por caminhos diferentes, ambos apontam a necessidade de uma regulamentação que dê conta de organizar a vida social, pois, do contrário, a tendência é que os mais fortes submetam os mais fracos. Para tanto, enquanto os socialistas apostam em uma reestruturação econômica, Durkheim insiste na necessidade de uma reestruturação moral. A diferença entre eles, portanto, diz respeito aos meios para alcançar uma sociedade mais justa.

Mas, a despeito do sentimento de justiça que permeia a sociologia durkheimiana, em todo o resto ela diverge do pensamento socialista, sobremaneira do socialismo marxista, já que Durkheim não vê nem a luta de classes nem a ideia de revolução senão como indícios de uma patologia social. Além disso, como se viu, Durkheim não apregoa a superação do Estado, como faz o marxismo. Para ele, o Estado é uma espécie de "cérebro social”, cuja importância reside em sua capacidade de organizar as representações difusas, espontâneas e muitas vezes irracionais engendradas no seio da sociedade civil ${ }^{8}$.

É certo que para o mestre francês a acentuação da divisão do trabalho constitui um dos traços fundamentais da sociedade moderna e que tal processo corrobora para a expansão do

\footnotetext{
7 Jean Leon Jaurès (1859-1914) foi colega de Durkheim na École Normale Supérieure. Ambos tornaram-se amigos e mantiveram contato por um longo período depois de formados. Jaurès se notabilizou como militante político, tornando-se um dois maiores expoentes do pensamento socialista francês. Durante o período que antecedeu a Primeira Guerra Mundial inclinou-se, de acordo com seu humanismo, para uma saída pacífica. Acabou sendo assassinado em um café de Paris, no dia 31 de julho de 1914, por Raoul Villain, um jovem nacionalista francês que desejava a guerra com a Alemanha. A perda do amigo, mas sobretudo as circunstâncias de sua morte, causaram em Durkheim um sentimento de profunda tristeza.

${ }^{8}$ Não é à toa que a concepção durkheimiana de Estado foi alvo de inúmeras críticas. A noção de intercâmbio entre Estado e sociedade civil foi vista por muitos de seus críticos como ingênua e demasiadamente organicista, já que não comportava uma discussão mais profunda sobre as relações de poder no interior daquele. Bernard Lacroix (1984), todavia, discorda dessa avaliação. Para o intérprete francês, as posições de Durkheim sobre o Estado, bem como sobre a política em geral, só podem ser devidamente compreendidas caso se considere a sua articulação com a esfera das representações coletivas.
} 
individualismo, visto por ele como um avanço em relação às organizações sociais tradicionais, nas quais a noção de indivíduo praticamente inexiste. Contudo, ressalta o autor, apesar do primado da esfera econômica no mundo moderno e dos perigos inerentes ao processo de individuação - como, por exemplo, o florescimento do egoísmo - é um erro acreditar que a moralidade não tenha qualquer função a desempenhar. Pelo contrário, cabe a ela impedir que os apetites insaciáveis dos seres humanos aflorem com toda sua força. Disso não se depreende que a solução durkheimiana se reduza à defesa da moralização pura e simples: conforme explicitou em diversas ocasiões, sobretudo em seus últimos trabalhos, no caso das sociedades complexas a moral tem como centro o próprio o indivíduo, isto é, o ser humano em geral, encorajando-o a reivindicar o direito de realizar plenamente seus desejos e inclinações pessoais ${ }^{9}$. A moralidade moderna, portanto, nada tem a ver com a moralidade opressora das sociedades tradicionais. Nesse sentido, observações críticas como as de Raymond Aron, segundo as quais o socialismo dukheimiano é em essência o "socialismo" de Augusto Comte, perdem todo sentido. Se Durkheim não é um socialista no sentido mais estrito do termo, também não deve ser tomado como um conservador - se por isso entendermos a defesa de uma sociedade na qual não haja espaço para as singularidades individuais -, muito menos como um liberal - comprometido com as forças incontroláveis do mercado. Como observa Giddens (1998), embora Durkheim tenha sido influenciado em maior ou menor grau por cada uma dessas correntes de pensamento, sua intenção é superá-las todas através da reformulação moral da sociedade, isto é, da promoção de novos valores, capazes de impor limites ao egoísmo humano sem, no entanto, sufocar as liberdades individuais. Isso só será possível, segundo Durkheim, à medida que a divisão do trabalho progredir e, concomitantemente, a sociedade tornar-se cada vez mais imanente ao indivíduo, visto que a emancipação do julgamento individual do julgamento coletivo constitui uma prerrogativa fundamental da vida moderna.

\section{RESUMO}

O presente artigo tem como objetivo analisar as posições do sociólogo francês Émile Durkheim frente às doutrinas socialistas, destacando suas impressões, suas críticas e as soluções por ele oferecidas aos dilemas enfrentados por seus representantes. Com isso,

\footnotetext{
${ }^{9}$ Referimo-nos, pois, àquilo que Durkheim denomina de "individualismo moral" ou "culto ao indivíduo", conforme exposto anteriormente no artigo.
} 
pretende-se resgatar uma discussão, que, já no final do século XIX, mas também em boa parte do século XX, ganhou notoriedade nos meios acadêmicos e intelectuais, sobretudo no continente europeu, suscitando assim um debate acerca das potencialidades e fragilidades do pensamento socialista.

Palavras-chave: socialismo, comunismo, liberalismo, Estado e corporações profissionais.

\begin{abstract}
This article aims to analyze the positions of the French sociologist Emile Durkheim front of socialist doctrines, highlighting their impressions, their criticism and the solutions that are offered to the dilemmas faced by their representatives. Thus, we intend to rescue a discussion which, at the end of the nineteenth century, but also in much of the twentieth century, gained notoriety in academic and intellectual circles, especially in Europe and inspire a debate about the potentials and weaknesses of socialist thought.
\end{abstract}

Keywords: socialism, communism, liberalism, State and professional corporations.

\title{
REFERÊNCIAS BIBLIOGRÁFICAS
}

ARON, Raymond. (2003), As Etapas do Pensamento Sociológico. Traduzido por Sérgio Bath. São Paulo, Martins Fontes.

DURKHEIM, Émile. (1975), “O Individualismo e os Intelectuais”, in: A Ciência

Social e a Ação. Traduzido por Inês Duarte Ferreira. São Paulo, Difel, pp. 235-250.

. (2002), Lições de Sociologia. Traduzido por Mônica Stahel. São Paulo, Martins Fontes.

(2005), O Suicídio. Traduzido por Alex Marins. São Paulo, Martin Claret. (2007), As Regras do Método Sociológico. Traduzido por Paulo Neves. São Paulo, Martin Fontes. . (2008), Da Divisão do Trabalho Social. Traduzido por Eduardo Brandão. São Paulo, Martins Fontes.

(2011), "O Estado", in M. Oliveira; R. Weiss (orgs.), David Émile Durkheim: A Atualidade de um Clássico. Traduzido por Márcio de Oliveira. Curitiba, UFPR, pp. 95-101.

FRIDMAN, Luis Carlos. (1993), Émile Durkheim e Max Weber: Socialismo. Rio de Janeiro, Ralumé-Dumará.

GIDDENS, Anthony. (1986), Durkheim. London, Fontana Press. 
- (1998), Política, Sociologia e Teoria Social: Encontros com o Pensamento Social Clássico e Contemporâneo. Traduzido por Cibele Saliba Rizek. São Paulo, Unesp.

. (2005), Capitalismo e Moderna Teoria Social. Traduzido por Maria do Carmo Cury. Lisboa, Presença.

LACROIX, Bernard. (1984), Durkheim y lo Político. México, Fundo de Cultura Económica.

JOAS, Hans. (2012), A Sacralidade da Pessoa: Nova Genealogia dos Direitos Humanos. Tradução de Nélio Schneider. São Paulo, UNESP.

TIRYAKIAN, Edward. (1962), Sociologismo y Existencialismo. Buenos Aires, Amorrortu. . (1980), "Émile Durkheim", in T. Bottomore; R. Nisbet (orgs.), História da Análise Sociológica. Traduzido por Waltensir Dutra. Rio de Janeiro, Zahar, pp. 252 316.

VÉRAS, Maura Pardini Bicudo. (2014), Introdução à Sociologia: Marx, Durkheim e Weber, Referências Fundamentais. São Paulo, Paulus.

ZEITLIN, Irving. (1973), Ideología y Teoria Sociológica. Buenos Aires, Amorrortu.

Recebido em: 12/08/2015

Aprovado em: 24/02/2016 